\title{
Metodo estatistikoak saiakera klinikoetan
}

\author{
Arkaitz Galbete \\ Nafarroako Unibertsitate Publikoa \\ arkaitz.galbete@unavarra.es
}

Onartua: $27 / 06 / 2013$

Laburpena: Saiakera klinikoak esperimentu estatistikoen artean kasu bereziak dira bere sekuentzia egiturarengatik eta saiakeraren unitateak gizakiak direlako. Honek erregulazio zorrotza eskatzen du eta datuen biltze eta tratatze prozesuan eragina du, askotan metodologia espezifikoa edo berria erabiliz gainera. Artikulu honetan, saiakera klinikoen diseinuan agertzen diren arazo estatistiko batzuk azaltzen dira, pazienteak tratamenduetan esleitzeko metodo esanguratsu batzuen bilduma bat egiten da eta azken urteotan garrantzia hartzen ari den inferentzia prozesu desberdin bat aurkezten da.

\begin{abstract}
Clinical trials are a special case of statistical experiments due to their sequential structure and the fact that the experimental units are patients. This requires a strict regulation with a big effect in the process of data collection and processing, often using specific methodology or a new one. In this article, some statistical issues in the design of clinical trials are explained, a collection of different significant patient randomization rules is made and a randomization based inference process is presented, a topic which is gaining importance in recent years.
\end{abstract}

\section{SARRERA}

Esan daiteke esperimentu diseinuen teoria modernoa 1920 inguruan garatu zela batez ere Fisherren lanekin landa esperimentuen alorrean, eta gero [1] liburuan bildutakoak. Saiakera kliniko bat esperimentu bat ere bada, eta helburu nagusi modura hartzen du tratamendu berri baten portaera hobea azaltzea, beste tratamendu ezagun batekin edo plazebo batekin alderatuz. Baina bi desberdintasun nagusi dauzka esperimentu klasiko baten aldean, nekazaritzan egiten diren landa esperimentuen aldean esaterako, beraien trataera estatistikoan garrantzi izugarria izanik. Esperimentazio unitateak gizakiak direlarik, saiakerak aldez aurretiko hausnarketa etiko garrantzitsuak eskatzen ditu. Horrengatik, erregulazio zorrotz bat egitera 
behartuta daude, bertan alderdi estatistikoan eragin handia duelarik; Amerikako FDA (Food and Drug Administration) delakoak edo Europako medikamentu agentziak araudi sakon eta zehatzak plazaratzen dituzte eta horiek halabeharrez bete behar dira saiakera kliniko guztietan. Horrez gain, landaesperimentu gehienetan datuek aldibereko tratamendua jasaten dute, baina saiakera kliniko batean, aldiz, pazienteak sekuentzialki iristen dira, denboran asko luzatuz askotan; honek datuen tratamendua asko baldintzatzen du, baina beste aukera asko ere irekitzen ditu. Paziente berri bat ailegatzean aurrekoen informazioa eskuragarri izan ohi da, eta posible izaten da informazio hau erabiltzea, besteak beste tratamendu baten nagusitasuna azkarrago antzemateko eta saiakera lehenago bukatzeko edo zenbait estatistikoen optimizazioa bilatzeko.

Kontuan hartuko ditugun saiakera klinikoetan egitura honakoa izango da. Pazienteak sekuentzialki iristen dira esperimentura eta zorizko esleipen erregela baten bidez aztertzen ari garen tratamendu bat esleitzen zaie. Ondoren, esleitutako tratamenduari pazienteak ematen dion erantzuna behatzen da. Prozesu honetan zorizko esleipenaren ezaugarriak dira gako, eta erregelaren aukeraketak zehaztuko ditu diseinuaren propietate gehienak. Bigarren atalean saiakera kliniko batean ager daitezkeen problema estatistiko desberdinak azaltzen dira eta horietan zorizko esleipenak duen garrantzia. Hirugarren atalean literaturan azaldutako esleipen erregela desberdinak aurkeztuko dira eta laugarren atalean egun geroz eta garrantzi handiagoa hartzen ari den inferentzia prozesu bat aztertuko dugu, zorizko erregelan oinarrituta.

\section{SAIAKERA BATEN EGITURA ETA PROBLEMA ESTATISTIKOAK}

Saiakera kliniko batek lau fase nagusi dauzka:

- 1. fasea: Tratamendua gizakietan lehenbiziko aldiz aplikatzen den epea da. Gizaki gutxi sartzen dira fase honetan (20-80) eta tratamendu berriaren segurtasuna bermatzea da hemen helburua. Dosi ezberdinen toxikotasuna ikertzen da, hurrengo fasean erabiltzeko.

- 2. fasea: Tratamenduaren eraginkortasuna neurtzen da. Paziente gehiago sartu ohi dira eta eraginkortasun aldetik dosi optimoa bilatzen da, beti toxikotasun maximo bat finkatuz.

- 3. fasea: Aurreko faseetan lortutako dosiekin gure tratamendu esperimentala beste tratamendu batekin edo plazebo batekin konparatzen da bere nagusitasuna frogatzeko. Hauxe da saiakeraren faserik handiena; hori dela-eta, paziente kopuru handia behar du eta askotan denbora askotan luzatu daiteke. 
- 4. fasea: Tratamendua onartu eta merkatuan jarri ondoren, jarraipena egiten da bestelako ondorioak neurtu eta aztertzeko.

Fase bakoitzak bere arazo eta tratamendu estatistiko desberdina dauka. Oro har, badaude arazo orokor batzuk, saiakera kliniko baten diseinuan kontuan hartu beharrekoak.

Alborapenak Ez da ahaztu behar saiakeraren azkeneko helburua tratamenduen arteko konparaketa egitea dela, eta konparaketa hau alboragabea izan beharko litzateke. Tratamenduen esleipenean zorizko erregela bat erabiltzeak alborapenen aurkako babes handia ematen du, baina askotan ez da nahikoa eta kontuan hartu behr dira diseinuan eta analisian beste hainbat alderdi ere.

Hasteko, datuen tratamenduan beharrezkoa da informazio-bilketaren uniformetasuna, batez ere pazienteen erantzunen neurketetan eta zenbait jatorri ezberdin elkartzen dituen saiakera batean. Ondoren, saiakeraren xehetasunak ezkutatu egin beharko litzaizkieke parte hartzen duten eragile guztiei, hau da, pazienteek eta medikuek ez lukete jakin beharko zein den aplikatu behar den tratamendua. Askotan ezinezkoa da medikuak ez jakitea zein den aplikatu behar den tratamendua, beharrezkoak diren prestakuntzengatik. Orduan, komenigarria da erantzunaren ebaluazioa egiten dutenek aplikatutako tratamendua ez jakitea. Medikuek tratamendua jakin edo asmatzeko gai direnean sortu dezaketen alborapenari hautaketaalborapena deritzo eta askotan alborapen hau zenbatu egiten da. 1 taulan irudikatu dira esleipen erregela desberdinek hautaketa alborapenean duten balioa, lagin tamaina eta tratamenduen arrakasta probabilitate ezberdinentzat.

Beste alborapen-iturri inportantea koaldagaiak dira. Esperimentua hasterakoan tratamenduen emaitzan eragina izan dezaketen aldagaiak finkatzen dira, baina gerta daiteke aldagai inportanteren bat kanpoan uztea eta horrek eragina izatea bukaeran neurtzen dugun emaitzan. Adibide gisa, medikuak pentsa lezake pazientearen adinak ez duela eraginik tratamenduaren emaitzan. Kasu horretan aldagai hau ez litzateke kontuan hartuko esperimentuaren diseinuan. Era berean, gerta liteke tratamendu baten emaitzak hobeagoak izatea jende helduaren artean jende gaztearen artean baino; ondorioz paziente heldu gehiago izango lituzkeen tratamenduak osoko emaitza hobea edukitzea. Kasu honetan emaitza erabat alboratua egongo litzateke adinaren eraginagatik. Alborapen mota honi ustekabeko alborapena deitzen zaio eta horrelakorik ekiditeko, esperimentuaren lehen faseetan egindako analisia funtsezkoa da, diseinuan sartu beharreko intereseko aldagaiak ondo hautatzeko.

Hurrengo taulan aurkezten dira hautaketa alborapenen balioak, ondoren azaldutako diseinu batzuetarako arrakasta probabilitate ezberdinekin. 
1. taula. Play-the-winner, Drop-the-loser eta Hu-Zhang erregelen hautaketaalborapena, probabilitate bikote eta paziente kopuru bakoitzeko ikerlariak hurrengo tratamendua zein izango den asmatzeko batezbesteko probabilitatea (desbiderapen estandarra).

\begin{tabular}{rrr|lll}
\hline & & & PTW & DTL & Hu-Zhang \\
\hline$p_{1}$ & $p_{2}$ & $n$ & & & \\
\hline 0.8 & 0.8 & 50 & $0.64(0.119)$ & $0.58(0.071)$ & $0.68(0.077)$ \\
\hline & & 100 & $0.62(0.1)$ & $0.58(0.051)$ & $0.66(0.058)$ \\
\hline 0.5 & 0.5 & 50 & $0.58(0.08)$ & $0.63(0.060)$ & $0.61(0.058)$ \\
\hline & & 100 & $0.56(0.058)$ & $0.63(0.042)$ & $0.59(0.042)$ \\
\hline 0.8 & 0.7 & 50 & $0.63(0.113)$ & $0.60(0.068)$ & $0.68(0.076)$ \\
\hline & & 100 & $0.62(0.093)$ & $0.61(0.050)$ & $0.66(0.060)$ \\
\hline 0.8 & 0.4 & 50 & $0.71(0.105)$ & $0.69(0.058)$ & $0.75(0.073)$ \\
\hline & & 100 & $0.72(0.082)$ & $0.71(0.044)$ & $0.75(0.057)$ \\
\hline & & 200 & $0.73(0.062)$ & $0.73(0.033)$ & $0.75(0.041)$ \\
\hline
\end{tabular}

Lagin tamaina Oso zaila da saiakera kliniko batean beharrezko den lagin tamaina aurreikustea, gehienetan ezezagunak diren parametroen menpe dagoelako tamaina hori, eta horrez gain, denboran prozesu luzea delako eta askotan indibiduo asko galtzen direlako kausa desberdinengatik. Hala eta guztiz ere, komenigarria da saiakera hasi aurretik paziente kopuru bat ezartzea helburu bezala. Normalean, inferentzia prozesuan erabiliko den hipotesi-testak, hipotesi alternatibo ezagun batera batentzat, potentzia balio bat eskuratzeko finkatzen da. Lagin tamaina handiagoek potentzia handiagoak ematen dituzte, baina kostu ekonomiko eta operazionalengatik, lagin tamaina hau asko estutu ohi dira. Erregulazioak ohiko balio bezala ezartzen du 1. motako erroreak 0.05 ekoa izan behar duela, eta potentziak 0.8 edo $0.9 \mathrm{koa}$; hala ere, balio hauek, alda daitezke tratatzen ari garen prozeduraren garrantzi eta kaltegarritasunaren arabera.

Bestalde, esperimentuaren sekuentzia egiturak posible egiten du saiakeraren erdian zenbait ikuskapen egitea, tratamendu bat berehala era na- 
barian nabarmenduz gero saiakera lehenago bukatzeko. Ikuskapen hauek ondo planifikatu behar dira eta horretarako metodo desberdinak aurkeztu dira literaturan, planifikazio ezak gure osoko testean 1. motako errorearen hazkuntza handia ekar lezakeelako.

2. taula. Simulatutako potentzia eta itxarondako porrot kopurua (desbiderapen estandarra) 10.000 errepikapen. Rosenberger eta Hu (2004).

\begin{tabular}{rrr|rc|cc|cc}
\hline & & & \multicolumn{2}{|c|}{ CA } & \multicolumn{2}{c|}{ Hu-Zhang } & \multicolumn{2}{c}{ DTL } \\
\hline \multicolumn{1}{c}{$p_{1}$} & \multicolumn{1}{c|}{$p_{2}$} & \multicolumn{1}{c|}{$\mathrm{n}$} & Potentzia & Porrotak & Potentzia & Porrotak & Potentzia & Porrotak \\
\hline 0.9 & 0.3 & 24 & 90 & $10(2.4)$ & 91 & $8(2.1)$ & 90 & $7(1.8)$ \\
0.9 & 0.5 & 50 & 90 & $15(3.2)$ & 91 & $13(2.6)$ & 89 & $12(2.6)$ \\
0.9 & 0.7 & 162 & 90 & $32(5.1)$ & 90 & $31(4.8)$ & 89 & $27(4.6)$ \\
0.9 & 0.8 & 532 & 90 & $80(8)$ & 91 & $79(8)$ & 89 & $73(8)$ \\
0.7 & 0.3 & 62 & 90 & $31(4.0)$ & 90 & $28(3.5)$ & 89 & $27(4.1)$ \\
0.7 & 0.5 & 248 & 90 & $99(7.8)$ & 90 & $97(7.5)$ & 89 & $93(8.0)$ \\
0.5 & 0.4 & 1036 & 90 & $570(16)$ & 90 & $567(16)$ & 89 & $565(16)$ \\
0.3 & 0.1 & 158 & 90 & $126(5.1)$ & 90 & $122(5.4)$ & 90 & $124(5.3)$ \\
0.2 & 0.1 & 532 & 90 & $452(8)$ & 90 & $448(9)$ & 90 & $451(8)$ \\
\hline
\end{tabular}

\section{METODO MOLDAGARRIAK}

Aurreko atalean saiakera kliniko baten diseinuan kontuan hartu beharreko hainbat alderdi aztertu dira, baina prozesu oso inportante bat da, hain zuzen askotan behar adina garrantzia ematen ez zaion prozesua, pazienteen zorizko esleipen erregela. Metodo desberdin asko aurkeztu dira, batez ere azkeneko 40 urteetan, helburu eta egitura desberdinekin. Zorizko erregelak sailkatzeko arau ohikoena erabilitako informazio kantitatea da, hots, esperimentuaren sekuentzia egituragatik, aurreko tratamenduen esleipen edo erantzunak erabili ahal dira hurrengo esleipenak egiteko eta horregatik, metodo hauek moldagarriak deitzen dira.

Txanpon orekatuaren jaurtiketa da metodorik sinpleena eta zori maximoa azaltzen duena. Pazientea ailegatzerakoan bi tratamenduen artean zozketatzen da 0.5 eko probabilitatea edukita tratamendu bakoitzerako. Metodo honek, esan bezala, zori maximoa bermatzen du eta esleipen guztiak independenteak dira; horrek abantaila estatistiko ugari dakartza. Hala ere, arazo handi bat dauka, bi tratamenduen esleipen kopuruen artean desoreka handiak ekar ditzakeelako eta horrekin lotuta estimatzaileen bariantzak oso handiak dira. Arazo hau ekiditeko, bloke permutatuen diseinua aurkeztu 
zen, zeinetan esleipen erregela txanpon orekatua izaten jarraitzen duen, baina pazienteak $2 \mathrm{~b}$ tamainako bloketan banatzen dira. Bloke bakoitzean tratamendu bat $\mathrm{b}$ aldiz izendatzen denean, blokea osatu arte hurrengo pazienteak beste tratamendura esleitzen dira. Aldaketa honek esleipen kopuruen arteko desoreka konpondu egiten du, baina esleipen asko era deterministakoan egiten dira, horrek sor ditzakeen alborapenekin. Hala ere, diseinu hau da praktikan gehien erabiltzen dena.

Diseinu moldagarrien artean lehenbizitarikoa Efronen diseinua izan zen. Diseinu honek, alboratutako erregela bat erabiltzen du tratamenduen esleipenen kopuruen berdintasuna aurkitzeko. Txanpon albodatua deritzote erregela horri. Paziente bat datorrela, honelako probalitateekin esleitzen zaio tratamendua:

$$
\delta_{n}= \begin{cases}1 / 2, & \text { bi tratamenduak kopuru berean aplikatu dira } \\ p, & \text { 2. tratamendua gehiagotan aplikatu da } \\ 1-p, & \text { bestela }\end{cases}
$$

$p>1 / 2$ izanik. Erregela honek tratamenduen esleipenen kopuruen arteko diferentziak murrizten ditu, gehiagotan aplikatu denari probabilitate gutxiago ezarriz. Baina iraganeko informazioaren erabilerak ere prozesua konplexutasuna gehitzen dio, esleipenen arteko dependentzia sartzen dugulako.

Esan dugu metodo moldagarriek aurreko informazioa erabiltzen dutela hurrengo esleipenak egiteko, eta Efronen diseinua horren adibide argi bat da. Hala ere, ez du biltzen eskuragarri daukagun informazio guztia, pazienteek tratamenduei emandako erantzunetatik guztiz independentea delako. Aurreko esleipenez gain, aurreko erantzunak erabiltzen dituzten metodoei erantzunaren araberako moldagarriak deritze eta helburu bezala tratamendu-izendapenen kopuruen berdintzea izan beharrean, esperimentuan zehar gertatutako erantzunen arabera moldatzen ditu izendapen kopuruak. Hau da, esperimentazioan tratamendu batek emaitza hobeak emanez gero, esleipen kopurua tratamendu horretarantz alboratzen da da, esperimentuaren kutsu etikoa nabarmenduz. Talde honetan ontzietan oinarritutako bi diseinu nabarmentzen dira, play-the-winner erregela eta drop-the-loser erregela. Lehenengoa aurkeztutako erantzunari egokitutako lehenengoetariko diseinua izan zen eta bera da literaturan gehien agertu dena. Egitura bakuna du, ontzian $a$ bola dauzkagu tratamendu bakoitzeko; pazientearen etorreran bola bat ateratzen da, tratamendu hori aplikatu eta bola bueltatu egiten da. Pazientearen erantzuna arrakastatsua baldin bada, aplikatutako tratamenduaren $b$ bola gehitzen dira; porrota egiten badu, ordea, beste tratamenduaren $b$ bola gehitzen dira. Erregela honek emaitza onak dakartzan tratamendua saritzen du, bere bola kopurua handituz eta ondorioz gehiagotan aplikatzeko aukerak handituz; bestalde gaizki funtzionatuz gero, zigortu egiten du, kon- 
trako tratamenduaren bola proportzioa handituz. Beste antzeko diseinu bat da drop-the-loser erregela. Pazientearen etorreran bola bat ateratzen da, dagokion tratamendua aplikatu eta erantzuna begiratzen da. Arrakasta lortu baldin badu, bola bueltatu egiten da; porrota egin baldin badu, ez da bueltatzen. Ontzia bolarik gabe ez geratzeko beste bola mota bat gehitzen da, immigrazioko-bolak. Bola hauek finkatutako kopuru batean daude ontzian eta hauetako bat ateratzean tratamenduei lotutako bolen unitate bat gehitzen da, ez da tratamendurik aplikatzen eta bola bueltatu egiten da hurrengo ateratze baterako. Beste diseinu sorta garrantzitsu bat dago. Hau, ontzietan oinarritu beharrean, tratamenduen esleipenen probabilitateak funtzio moldagarri batzuen menpe ematen da. Adibide esanguratsuetako bat da [4] artikuluan aurkeztutako Hu-Zhang erregela, edozein tratamendu esleipenen proportziora bideratu daitekeelako eta propietate onak erakutsi dituelako bai potentzia eta bai etika aldetik. 2. taulan ikus daiteke, hala gertatu dela.

Azken urteotan beste metodo moldagarri batzuk agertu dira, CARA (Covariate-adjusted Response-Adaptive) deitutakoak. Metodo hauetan pazienteen esleipenak egiteko aurreko esleipenak, erantzunak eta kobariableak erabiltzen dira, etorri berri den pazientearena barne. Aldagai berri hauen agerpenak diseinuaren egituraren konplexutasuna handitzen du, baina horrek ondoren analisi zehatzagoak egitera bermatzen du ere, pazienteak taldetan banatu ahal izatea eta inferentzia mailaka egitea posiblea egiten du.

\section{INFERENTZIA EZ-PARAMETRIKOA}

Sarreran esana da saiakera klinikoak beste esperimentu estatistikoetatik nabarmen desberdintzen direla zenbait arrazoiengatik. Sekuentzia egitura eta alderdi etikoak asko baldintzatzen dute esperimentuaren analisi estatistikoa. Horrez gain, laginketa metodoa ere nahiko berezia da. Populazio eredu arrunt batean erreferentziazko populaziotik (edo populazioetatik) zorizko laginketa arruntaren bidez lortzen da lagina. Saiakera kliniko batean, aldiz, nahiko eztabaidagarria da eredu honen onarpena. Hautatuak izateko baldintzak betetzen dituzten pazienteek osatzen dute populazioa teorikoa. Horietatik, es-perimentuan parte hartzen ari diren zentroetako batean aurkitzen direnak soilik daude eskuragarri, eta horrez gain, gerta daiteke pazienteak saiakeran parte hartzeko onespena ez ematea edo medikuek baztertzea. Ondorioz, lagina onespena ematen duten eta medikuak onartutako pazienteek sortzen dute. Nabaria denez, lagina lortzeko prozesu hau ez da zorizkoa eta normalean onartu egiten den populazio eredutik urrun dago. Horregatik, Rosenberger eta Lachini (2002) jarraituz, populazio ereduan oinarritzen ez den inferentzia metodo bat proposatzen da. Metodo honetan, zorizko prozesu bakarra pazienteen esleipena da, eta horretan oinarritzen da inferentzia egiteko. Hautaketa honek analisia zaildu egiten du, baina koherenteagoa da esperimentuaren egiturarekin. 
Permutazio test bat proposatzen da, hipotesi parametrikorik gauzatu gabe. Honela hipotesi-test hau aurkeztu genezake.

H0 : Bi tratamenduak baliokideak dira, hau da, bata edo bestearen esleipenak ez du eraginik pazientearen erantzunean.

H1 : Bi tratamenduak ez dira baliokideak.

Hau da, hipotesi nuluari eutsita, tratamendu-esleipenak ez die pazienteen erantzunari eragiten eta beraz erantzun hauek deterministatzat har daitezke, prozesu guztian zori bakarra esleipena izanik. Honengatik, esleipen erregela eta bere ezagutza oinarrizkoa da inferentzi mota honetan. Metodo honekin, tratamenduen esleipenak finkatutako erantzunekin permutatzen dira eta estatistikoaren balioa kalkulatzen da permutazio bakoitzerako.

P-balioa lortzeko, batu egiten dira estatistikoaren balioa balio esperimentala baino handiagoa duten permutazioak gertatzeko probabilitateak. Hurrengo adibidean kasu erraz bat azaltzen da, 6 paziente eta 2 tratamenduekin, permutazio guztiak gertatzeko probabilitate bera dutela onartuz.

Adibidea: Demagun 6 paziente dauzkagula bi tratamendutan banatzeko eta gure emaitza esperimentala honakoa dela: , lehenengo tratamenduan $\mathrm{A}=8$, $\mathrm{B}=12, \mathrm{C}=9$ emaitzak izan ditugu eta bigarrengoan $\mathrm{D}=10, \mathrm{E}=5, \mathrm{~F}=7$. Orduan emaitza hauek 2 taldetan permutatzen dira 3 paziente mantenduz bakoitzean; bestetik, estatistikoaren balioa kalkulatzen da permutazio bakoitzerako, erabilitako estatistikoa bi taldeen batez bestekoen arteko diferentzia izanik.

\begin{tabular}{|c|c|c|c|c|}
\hline 1 taldea & $\mathbf{2}$ taldea & $\bar{X}$ & $\bar{Y}$ & $\bar{X}-\bar{Y}$ \\
\hline $\mathrm{ABC}$ & $\mathrm{EFG}$ & $29 / 3$ & $22 / 3$ & $7 / 3$ \\
\hline $\mathrm{ABD}$ & $\mathrm{CEF}$ & $28 / 3$ & $23 / 3$ & $5 / 3$ \\
\hline $\mathrm{ABE}$ & $\mathrm{CDF}$ & $24 / 3$ & $27 / 3$ & -1 \\
\hline $\mathrm{ABF}$ & $\mathrm{CDE}$ & $27 / 3$ & $24 / 3$ & 1 \\
\hline $\mathrm{ACD}$ & $\mathrm{BEF}$ & $26 / 3$ & $25 / 3$ & $1 / 3$ \\
\hline $\mathrm{ACE}$ & $\mathrm{BDF}$ & $22 / 3$ & $29 / 3$ & $-7 / 3$ \\
\hline $\mathrm{ACF}$ & $\mathrm{BDE}$ & $25 / 3$ & $26 / 3$ & $-1 / 3$ \\
\hline $\mathrm{ADE}$ & $\mathrm{BCF}$ & $21 / 3$ & $30 / 3$ & -3 \\
\hline $\mathrm{ADF}$ & $\mathrm{BCE}$ & $24 / 3$ & $27 / 3$ & -1 \\
\hline $\mathrm{AEF}$ & $\mathrm{BCD}$ & $20 / 3$ & $31 / 3$ & $-11 / 3$ \\
\hline EFG & $\mathrm{ABC}$ & $22 / 3$ & $29 / 3$ & $-7 / 3$ \\
\hline$\vdots$ & $\vdots$ & $\vdots$ & $\vdots$ & $\vdots$ \\
\hline p-balioa=P $(|\bar{X}-\bar{Y}| \geq 7 / 3)=\frac{8}{20}=0.4$. & &
\end{tabular}


Bukatzeko, p-balioa gure estatistikoaren balioen esperimentala baino balio absolutu handiagoko permutazioen portzentaia kalkulatuz lortzen da; kasu honetan, simetria aplikatuz, 20 permutaziotatik $8 \mathrm{k}$ ematen dute estatistikoaren balio handiagoa, hipotesi nulua onartuz.

Inferentzi metodo hau oso eztabaidatua izan da literatura estatistikoan, Fisherrek aurkeztu zuenetik. Egokitasuna alde batera utzita, bi arazo nagusi daude. Alde batetik, normalean modu honetako testak nahiko kontserbakorrak izaten dira, hau da, asko kostatzen zaie hipotesi nulua deuseztatzea. Bestalde, eta hau izan da segur aski bere erabilera murritzaren kausa, konputazionalki oso astunak dira, tratamenduen esleipenen permutazio guztiak kalkulatu behar direlako eta horrez gain, permutazio bakoitzaren probabilitatea ere kalkulatu behar delako; ondorioz, algoritmoak asko moteltzen dira eta horregatik askotan paziente kopurua handitzen denean p-balioak ez dira denbora praktiko batean eskuragarriak. Lagin tamaina handietan gertatzen den arazoari aurre egiteko bi jokabide nagusi erabili dira literaturan. Bata, diseinuaren propietateak erabilita errepikapen formulak erabiltzea konputazio algoritmoak azkartzeko; metodo ohikoenean, estatistikoaren banaketa asintotikoa lortu eta erabiltzea da hurbilpen bezala. Hala ere, banaketa asintotikoaren bilaketa ez da erraza egitura honetan, pazienteen erantzunen multzoa finkatuta datorrelako. Izan ere, multzo bakoitzerako estatistikoa asko aldatzen da eta nahiko zaila da erantzun multzo guztietarako emaitza homogeneo bat lortzea.

\section{ERREFERENTZIAK}

[1] FISHER R.A. 1935. Design of Experiments. Oliver and Boyd, Edimburgh.

[2] ROSENBERGER W.F. eta LACHIN J.M. 2002. Randomization in Clinical Trials. Theory and Practice. Wiley, New York.

[3] ROSENBERGER W.F. eta HU F. 2004 «Maximizing power and minimizing treatment failures in clinical trials» Clinical Trials, 1, 141-147.

[4] HU F. eta ZHANG L.X. 2004. «Asymptotic properties of doubly adaptive biased coin designs for multitreatment clinical trials». The Annals of Statistics, 32, 268-301. 